\title{
Effect of Group B Streptococcal Sepsis on Diaphragmatic Function in Young Piglets
}

\author{
TIMOTHY D. MURPHY, RONALD L. GIBSON, THOMAS A. STANDAERT, DENNIS E. MAYOCK, \\ AND DAVID E. WOODRUM \\ Division of Neonatal and Respiratory Diseases, Department of Pediatrics, University of Washington School of \\ Medicine, Seattle, Washington 98195
}

\begin{abstract}
Recent studies indicate that diaphragmatic pressure generation (Pdi) is impaired by bacterial infection. However, group B streptococcus (GBS) had no effect on Pdi when infused into 4-wk-old piglets. As responsiveness to GBS is age-dependent, we therefore studied the acute effect of GBS infusion on Pdi, using a younger, 2-wk-old piglet model. Using trans-Pdi with phrenic nerve stimulation, we studied the effect of continuous GBS infusion in seven anesthetized, spontaneously breathing 2 -wk-old piglets. Pdi was measured under baseline conditions $\left(50 \% \mathrm{O}_{2} /\right.$ $50 \% \mathrm{~N}_{2}$ ) and at 1,2 , and $4 \mathrm{~h}$ of GBS infusion. GBS was infused at a rate which caused a doubling of the pulmonary artery pressure but which avoided hypotension or acidosis-both of which can decrease Pdi. In addition, the piglets were kept hyperoxic $\left[\mathrm{PaO}_{2}>13.3 \mathrm{kPa}(100\right.$ torr $\left.)\right]$, and no piglet with hypercapnia $\left[\mathrm{PaCO}_{2}>8.7 \mathrm{kPa}(65\right.$ torr)] was included, as hypoxia and hypercapnia can also cause respiratory muscle dysfunction. For the GBS group, diaphragmatic contractility declined significantly by $1 \mathrm{~h}$ at $30-, 50-$, and $100-\mathrm{Hz}$ stimulation frequency and, by $2 \mathrm{~h}$, was significantly decreased at all frequencies. We conclude that 2-wk-old piglets, in contrast to 4-wk-old piglets, demonstrate a decline in Pdi during GBS infusion. These data demonstrate an age-related response to GBS in the piglet. This finding implies that a decline in Pdi during acute GBS infusion is not due to a secondary effect from shock (i.e. acidosis, hypercapnia, or hypoxemia) or due to the catabolic effects of a chronic infection, but is due to a direct effect of sepsis on diaphragmatic muscle function. (Pediatr Res 33: 10-14, 1993)
\end{abstract}

\section{Abbreviations}

BP, blood pressure

cfu, colony-forming units

$\mathrm{CO}$, cardiac output

FRC, functional residual capacity

GBS, group B streptococcus

$\mathrm{HR}$, heart rate

$\mathrm{P}_{\mathrm{PA}}$, pulmonary artery pressure

Pdi, transdiaphragmatic pressure generation

Qdi, diaphragmatic blood flow

$R R$, respiratory rate

$\dot{\mathrm{V}}_{\mathrm{E}}$, minute ventilation

$V_{\mathrm{r}}$, tidal volume

Paw, airway pressure

Pga, intragastric pressure

ANOVA, analysis of variance

Received February 21, 1992; accepted September 14, 1992.

Correspondence: Timothy D. Murphy, MD, Department of Pediatrics, RD-20, University of Washington School of Medicine, Seattle, WA 98195.

Supported in part by ALA of Washington, NIH Grant HL 39157, and $\mathrm{MCH}$ Grant 000955 .

\author{
$\mathrm{TNF} \alpha$, tumor necrosis factor $\alpha$ \\ $\mathrm{PaO}_{2}$, arterial $\mathrm{O}_{2}$ tension \\ $\mathrm{PaCO}_{2}$, arterial $\mathrm{CO}_{2}$ tension
}

Systemic bacterial infections can cause respiratory muscle impairment (1-3). Studies of this problem have focused on the effect of either an overwhelming infection (i.e. septic shock) or a chronic infection (i.e. $>2$ d) on diaphragmatic contractility (13 ). Chronic infections can alter muscle structure, but the reason for altered diaphragmatic function after only hours of sepsis is unknown (4-6). It is unknown if bacteria exert a direct effect on muscle function or if the changes are due to alterations in substrate delivery, oxygenation, blood flow, or acid/base status or via the release of inflammatory mediators.

We recently demonstrated that GBS had no deleterious effect on force generation of the 4-wk-old piglet diaphragm (7). Our initial study examined the acute effects of a 4-h infusion of GBS given at a rate that avoided shock. Our assumption was that an alteration in Pdi during bacteremia without alterations in substrate delivery, oxygenation, Qdi, or acid/base status would imply that the altered contractility was due to a local effect of bacteria or inflammatory mediators on the muscle. However, under these experimental conditions, the 4-wk-old piglet demonstrated no change in Pdi (7).

GBS is highly lethal in the newborn human but is not associated with clinical disease in children greater than $3 \mathrm{mo}$ of age (8). Rats also exhibit an age-related response to GBS (9). Developmental changes in piglet response to GBS are unknown, but the age-related susceptibility to GBS in humans and rats led us to examine the effects of GBS on diaphragmatic force generation in a younger piglet. We therefore repeated our study of the acute effect of GBS infusion on Pdi in younger, 2-wk-old piglets, using an identical experimental protocol. The GBS infusion dose was again set to avoid acidosis, hypoxemia, hypercapnia, or hypotension-conditions shown to reduce Pdi in several animal models $(10-14)$. We hypothesized that GBS infusion, without shock, would cause a decrease in Pdi in the 2-wk-old piglet.

\section{MATERIALS AND METHODS}

Animal preparation. Fifteen mixed-breed piglets (14-d old, range 11-18 d) were studied in accordance with $\mathrm{NIH}$ and institutional guidelines regarding animal research. Animals in the two experimental groups were not different in age or weight (wt \pm SD): GBS group, mean age $=14 \mathrm{~d}$ (range $11-18 \mathrm{~d}$ ), mean body weight $=5.2 \pm 1.1 \mathrm{~kg}$; control group, mean age $=14 \mathrm{~d}$ (range 11-17 d), mean body weight $=4.1 \pm 0.8 \mathrm{~kg}$. Animals were anesthetized with chloralose $(45 \mathrm{mg} / \mathrm{kg})$ and urethane $(200$ $\mathrm{mg} / \mathrm{kg}$ ) i.v., anticoagulated with heparin (1000 IU i.v.), and studied in the supine position. Small additional doses of anes- 
thetic (chloralose $5-7 \mathrm{mg} / \mathrm{kg}$, urethane $30-50 \mathrm{mg} / \mathrm{kg}$ ) were given if the animal developed jaw clonus. The piglets were required to have an arterial $\mathrm{pH}>7.25, \mathrm{a} \mathrm{PaO}_{2}>13.3 \mathrm{kPa}$ (100 torr) in $50 \%$ oxygen, and a $\mathrm{PaCO}_{2}<8.7 \mathrm{kPa}$ ( 65 torr), at baseline and throughout the study, for inclusion. The piglets breathed through a surgically placed tracheostomy tube attached to a Hans Rudolph miniature two-way nonrebreathing valve (model 2384, Hans Rudolf, Inc., Kansas City, MO). $\dot{\mathrm{V}}_{\mathrm{E}}$ was measured by electronic integration (Hewlett Packard 8815A, Hewlett Packard, North Hollywood, CA) of the respiratory flow trace from a Fleisch pneumotachometer. A 4.1 French pediatric pigtail catheter (Cook Inc., Bloomington, IN) was positioned in the left ventricle via the left carotid artery using fluoroscopy. Femoral arterial catheters were placed to permit sampling of blood for measurement of gas tensions and $\mathrm{pH}$ (Corning $170 \mathrm{pH} /$ Blood Gas Analyzer, Corning Medical, Medfield, MA), BP, and withdrawal of microsphere reference samples. A left internal jugular venous catheter was used for infusion of bacteria, and the right internal jugular vein was used to position a No. 5 French Swan-Ganz thermodilution catheter with $10-\mathrm{cm}$ proximal port (American Edwards Laboratories, Irvine, CA) in a branch of the left pulmonary artery to determine $\mathrm{CO}, \mathrm{P}_{\mathrm{PA}}$ and for sampling of mixed venous blood and monitoring of central body temperature. Measures of CO (model 9520A Cardiac Output Computer, American Edwards Laboratories, Irvine CA) were obtained in triplicate using $2-\mathrm{mL}$ aliquots of iced $5 \%$ dextrose in water. The piglet's temperature was maintained between $37.5^{\circ}$ and $39.5^{\circ} \mathrm{C}$ by a radiant heat warmer.

Measurement of diaphragmatic contractility. Diaphragmatic contractility was assessed by measuring the trans-Pdi during airway occlusion and bilateral transvenous phrenic nerve stimulation (Grass S48 Stimulator, Grass Medical Instruments, Quincy, MA) at supramaximal voltage at frequencies of 20,30 , 50 , and $100 \mathrm{~Hz}$ (11). Pdi is obtained by subtracting the Paw from the $\mathrm{Pga}(\mathrm{Pdi}=\mathrm{Pga}-\mathrm{Paw})$, using a Validyne differential pressure transducer (model MP45-2, Validyne Engineering Corp., Northridge, $\mathrm{CA}$ ) (15). Pga was measured by positioning a thin-walled latex balloon-tipped catheter $(1.65-\mathrm{mm}$ internal diameter) containing 0.5 - to $0.8-\mathrm{mL}$ of air in the stomach. Paw was measured via an 18-gauge needle inserted in the tracheostomy tube proximal to the nonrebreathing valve.

To ensure a consistency in diaphragmatic muscle shortening, a rigid plaster cast covering the abdomen and lower third of the chest was applied during phrenic nerve stimulation. Between episodes of data gathering, the animals were allowed to breathe without restriction. To prevent the development of atelectasis, every $20-30 \mathrm{~min}$ the piglets were given three to five 2-s "sighs" to $2.9 \mathrm{kPa}\left(30 \mathrm{~cm} \mathrm{H}_{2} \mathrm{O}\right)$ pressure. Changes in diaphgram muscle length were indirectly assessed from end-expiratory lung volume, or FRC, as measured by the nitrogen washout technique (16).

Blood flow determination. Qdi was measured with radiolabeled microspheres, 15 microns in diameter, labeled with either ${ }^{46} \mathrm{Sc}$, ${ }^{95} \mathrm{Nb},{ }^{103} \mathrm{Ru},{ }^{113} \mathrm{Sn}$, or ${ }^{141} \mathrm{Ce}$ (Dupont Co., Wilmington, DE), injected into the left ventricle over a 30 -s period, with a reference flow sample withdrawn from the femoral artery (17). Adequate mixing of the microspheres within the blood was checked by comparing the right and left kidney samples. If the cpm of the two kidneys differed by more than $15 \%$, the data were not used (no animals were excluded). A reference sample, withdrawn starting $5 \mathrm{~s}$ before microsphere injection and for $30 \mathrm{~s}$ after completion of injection, was suspended in agar. Following completion of the experiment, the animal was killed and the costal and crural diaphragm were stripped of fat and tendon, weighed, put in counting vials, and, along with the reference samples, counted with a Packard Miniaxi Autogamma 5000 (Packard Instrument Co., Downers Grove, IL). Crossover between isotopes was corrected by using a spectral stripping technique (17) on a personal computer.

GBS strain and preparation. The GBS strain is a type III clinical isolate (COH-1) (18). The culture conditions, mode of resuspension in sterile nonbacteriostatic saline, tests of culture purity, measurement of bacterial concentrations, and quantitative blood cultures $(n=4)$ were performed as described previously (19).

Experimental protocol. In previous work, we determined that a dose of 2 to $8 \times 10^{8} \mathrm{cfu} / \mathrm{kg} / \mathrm{h}$ would approximately double the $\mathrm{P}_{\mathrm{PA}}$ and cause a 20-30\% drop in $\mathrm{CO}$ but not cause hypotension (7). Both experimental (GBS) and control piglets underwent baseline data collection after a 20 - to 30 -min stabilization period. In the GBS group, individual animals' infusion rates were determined by starting GBS infusion at $2 \times 10^{8} \mathrm{cfu} / \mathrm{kg} / \mathrm{h}$ and then increasing the infusion rate by $2 \times 10^{8} \mathrm{cfu} / \mathrm{kg} / \mathrm{h}$ every $10 \mathrm{~min}$ until the $P_{P A}$ was doubled, and then remaining at that infusion rate throughout the experiment. All GBS piglets doubled their $\mathrm{P}_{\mathrm{PA}}$ at an infusion rate between 2 and $8 \times 10^{8} \mathrm{cfu} / \mathrm{kg} / \mathrm{h}$ within 30 min of starting the infusion (mean $=5 \times 10^{8} \mathrm{cfu} / \mathrm{kg} / \mathrm{h}$ ). Data were then collected at 1,2 , and $4 \mathrm{~h}$ after the start of GBS infusion. In the control group, data were collected at 1,2 , and 4 $\mathrm{h}$ after the baseline run. Two of the control animals received sham saline infusion, and these animals showed no different response over time than the controls given no saline infusion. In previous studies from this laboratory, saline infusion is not associated with any change in Pdi over time $(11,12)$.

At each time point, data were collected in the following sequence: blood samples were drawn; BP, HR, RR, $\mathrm{V}_{\mathrm{T}}, \dot{\mathrm{V}}_{\mathrm{E}}$, and $\mathrm{P}_{\mathrm{PA}}$ were recorded; $\mathrm{CO}$ was determined; radiolabeled microspheres were injected; FRC was measured in triplicate; and the Pdi was determined. At the end of data collection, the animal was killed with an overdose of anesthesia and $\mathrm{KCl}$, and organ tissues were collected for blood flow determinations.

Statistical analysis. The data were collected over a 2-y period, with the GBS group data collected in the earlier part of this time period and the control data collected in the latter part. Over that 2-y period, average Pdi values obtained increased, such that the mean baseline Pdi at all frequencies was higher in the control group than in the GBS group. In addition, this larger-thanexpected variability in Pdi between animals led to a larger-thanexpected $\mathrm{SD}$, i.e. for $100-\mathrm{Hz}$ stimulation frequency, $\mathrm{SD}=29$ versus previously published $\mathrm{SD}=9$ (7). The reason for this upward trend in Pdi is not clear. No change in technique or methodology can account for it. The vendors claimed no changes in the care of the animals, i.e. feeding, iron supplementation, etc. (no antibiotics or steroids are given to the animals from our two vendors). A three-way (group, time, and frequency of stimulation) ANOVA was performed on Pdi to measure change over time. This analysis found a $p$ value by time equal to 0.011 , without any two- or three-way interactions. Because of the large variability in SD and differing baseline Pdi values, an ANOVA was then performed on Pdi, expressed as a percentage of baseline, for intergroup comparisons. This analysis found a $p$ value by group of $<0.002$, without any two- or three-way interactions. Significance by ANOVA was determined at the $p<0.02$ level, followed by intragroup comparisons by paired $t$ test, with significance determined at the 0.05 level (SPSS/PC + v3.0; SPSS, Inc., Chicago, IL). For all nonendpoint variables, $p$ values $<0.02$ for paired $t$ tests are presented for the readers' interest.

\section{RESULTS}

Force generation. For the GBS group, diaphragmatic contractility declined significantly by $1 \mathrm{~h}$ at $30-, 50-$, and $100-\mathrm{Hz}$ stimulation frequency and by $2 \mathrm{~h}$ was significantly decreased at all frequencies (Fig. 1A). At $4 \mathrm{~h}$, the force generation at 20 - and $30-\mathrm{Hz}$ stimulation frequencies remained significantly less than baseline. There was no consistent pattern of change in force generation in the control group (Fig. 1B). Pdi, as a percentage of baseline, was significantly different during GBS infusion between the GBS and control groups $(p=0.002)$ by ANOVA.

Ventilatory measures and gas exchange. Table 1 presents data on the $\mathrm{V}_{\mathrm{T}}, \mathrm{RR}, \dot{\mathrm{V}}_{\mathrm{E}}$, and FRC. Neither the GBS group nor the 

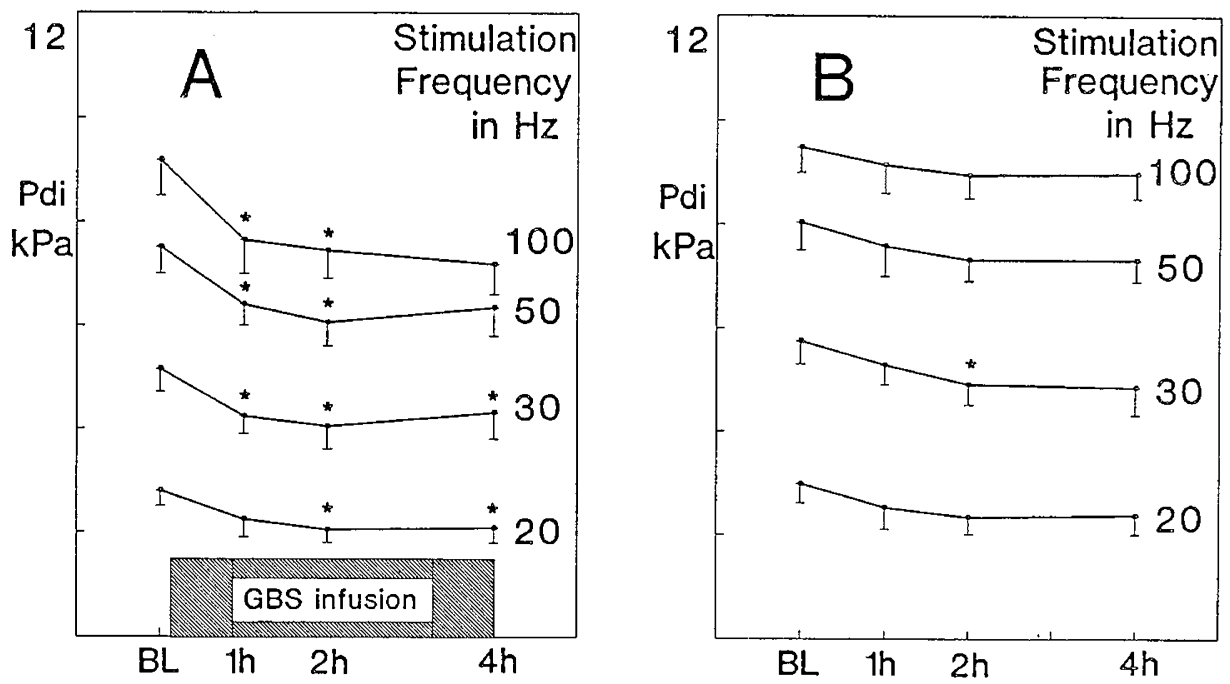

Fig. 1. Mean Pdi values $(\mathrm{kPa})$ for GBS $(A)$ and control $(B)$ piglets are plotted $v s$ time, in side-by-side graphs. Values are expressed as mean \pm SEM. $A$, GBS causes a loss of Pdi in the 2-wk-old piglet $(n=7) . B$, control 2-wk-old piglets demonstrate no consistent pattern of change in Pdi $(n$ $=8$ ). ${ }^{*}$ denotes $p<0.05$ for intragroup comparison (paired $t$ test) referenced to the baseline $(B L)$.

Table 1. Ventilatory measures*

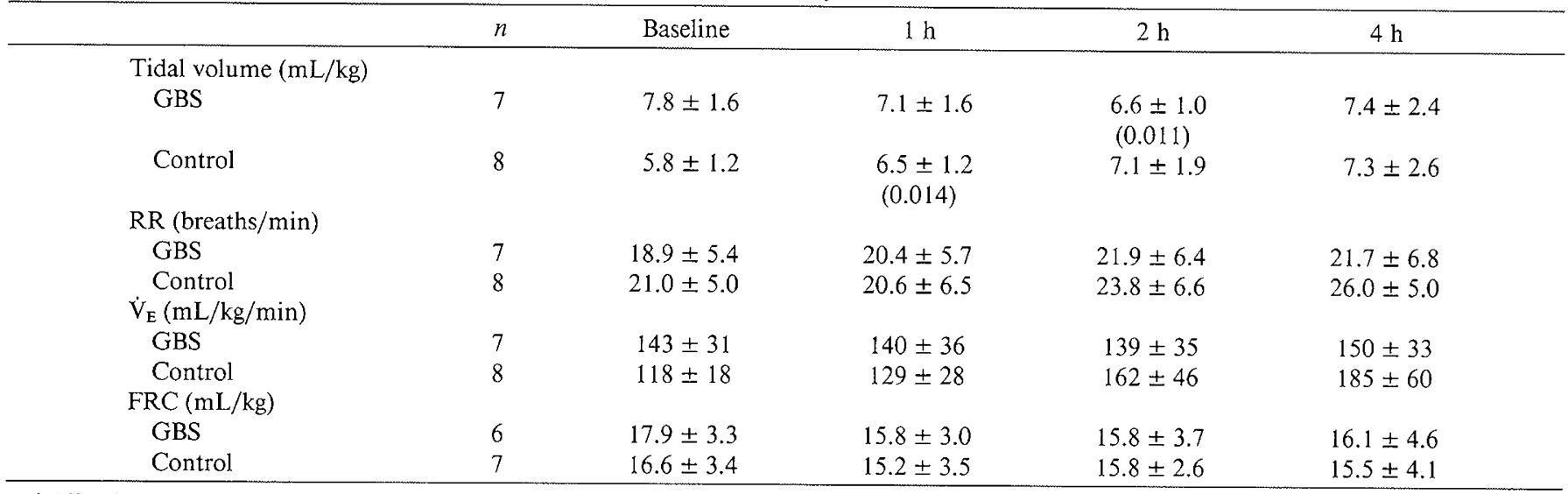

* All values are mean $\pm \mathrm{SD} ; n$, total no. of animals studied/experimental group; $p$ values are for paired $t$ tests $<0.02$ compared with baseline.

control group demonstrated any consistent trend in ventilatory measures. In the GBS-infused group, the $\mathrm{V}_{\mathrm{T}}$ decreased at $2 \mathrm{~h}$, whereas the respiratory rate and the $\dot{V}_{E}$ did not significantly change. The FRC did not change during GBS infusion. In the control group, the RR, $\dot{V}_{E}$, and FRC did not change, but the $V_{T}$ was noted to be significantly elevated at $1 \mathrm{~h}$. Table 2 presents data on gas exchange. In the GBS-infused group, the $\mathrm{pH}$ and $\mathrm{PaCO}_{2}$ did not change during GBS infusion. The $\mathrm{PaO}_{2}$ significantly declined by $4 \mathrm{~h}$ of GBS infusion, but the $\mathrm{PaO}_{2}$ remained above $13.3 \mathrm{kPa}$ (100 torr) in all animals. In the control group, no significant changes were noted in $\mathrm{pH}, \mathrm{PaCO}_{2}$, or $\mathrm{PaO}_{2}$.

Table 2. Blood gas measures*

\begin{tabular}{lccccc}
\hline & $n$ & Baseline & $1 \mathrm{~h}$ & $2 \mathrm{~h}$ & $4 \mathrm{~h}$ \\
\hline $\mathrm{pH}$ & & & & & \\
$\mathrm{GBS}$ & 7 & $7.36 \pm .06$ & $7.31 \pm .06$ & $7.34 \pm .05$ & $7.29 \pm .04$ \\
$\mathrm{C}$ Control & 8 & $7.33 \pm .08$ & $7.34 \pm .07$ & $7.35 \pm .07$ & $7.36 \pm .07$ \\
$\mathrm{PaCO}_{2}(\mathrm{kPa})$ & & & & & \\
$\mathrm{GBS}$ & 7 & $6.8 \pm 0.9$ & $7.5 \pm 1.0$ & $7.2 \pm 1.1$ & $7.5 \pm 1.4$ \\
$\mathrm{Control}$ & 8 & $7.5 \pm 0.9$ & $6.8 \pm 0.7$ & $7.0 \pm 1.4$ & $6.7 \pm 0.9$ \\
$\mathrm{PaO}_{2}(\mathrm{kPa})$ & & & & & \\
$\mathrm{GBS}$ & 7 & $26.9 \pm 3.6$ & $21.9 \pm 7.6$ & $24.6 \pm 5.1$ & $22.6 \pm 5.0$ \\
& & & & $(0.003)$ \\
Control & 8 & $25.6 \pm 3.9$ & $25.6 \pm 3.7$ & $25.6 \pm 3.4$ & $25.9 \pm 3.9$ \\
\hline
\end{tabular}

* All values are mean $\pm \mathrm{SD}$; $n$, total no. of animals studied/experimental group. $p$ values are for paired $t$ tests $<0.02$ compared with baseline $(1 \mathrm{~mm} \mathrm{Hg}=0.1333 \mathrm{kPa}$ ).
Hemodynamics and blood flow. Table 3 presents hemodynamic data. In the GBS-infused group, the $\mathrm{CO}$ progressively declined, falling by $36 \%$ after $4 \mathrm{~h}$ of infusion. By design, the $\mathrm{P}_{\mathrm{PA}}$ rose immediately and remained elevated throughout infusion. The HR showed an increase at $4 \mathrm{~h}$. In the control group, no changes were seen in $\mathrm{CO}$ or $\mathrm{P}_{\mathrm{PA}}$. The $\mathrm{HR}$ progressively increased throughout the study. Both costal and crural Qdi remained unchanged during the experiment in both the GBS-infused and control groups (Table 4).

\section{DISCUSSION}

Infusion of GBS led to a decrease of Pdi in the 2-wk-old piglet. This is the first description of bacteria leading to an acute alteration of Pdi without the development of shock, hypoxemia, or acid/base derangement. This result adds to existing evidence that bacterial infections can lead to an impairment of muscle contractility and demonstrates that the response to GBS is greater in younger animals.

The present study demonstrates that bacteremia will acutely lead to diminished Pdi without an alteration in oxygen delivery. Although the $\mathrm{PaO}_{2}$ was diminished significantly over time, the mean $\mathrm{PaO}_{2}$ remained above $13.3 \mathrm{kPa}$ (100 torr). Although the $\mathrm{CO}$ fell progressively by $36 \%$ over $4 \mathrm{~h}$, the decline in Pdi developed by $\mathrm{l} \mathrm{h}$. Moreover, the BP was maintained within 0.8 $\mathrm{kPa}(6 \mathrm{~mm} \mathrm{Hg})$ of baseline levels, and Qdi did not change from baseline or control during GBS infusion. Thus, impaired tissue oxygen delivery does not account for the alteration in Pdi. 
Table 3. Hemodynamic measures*

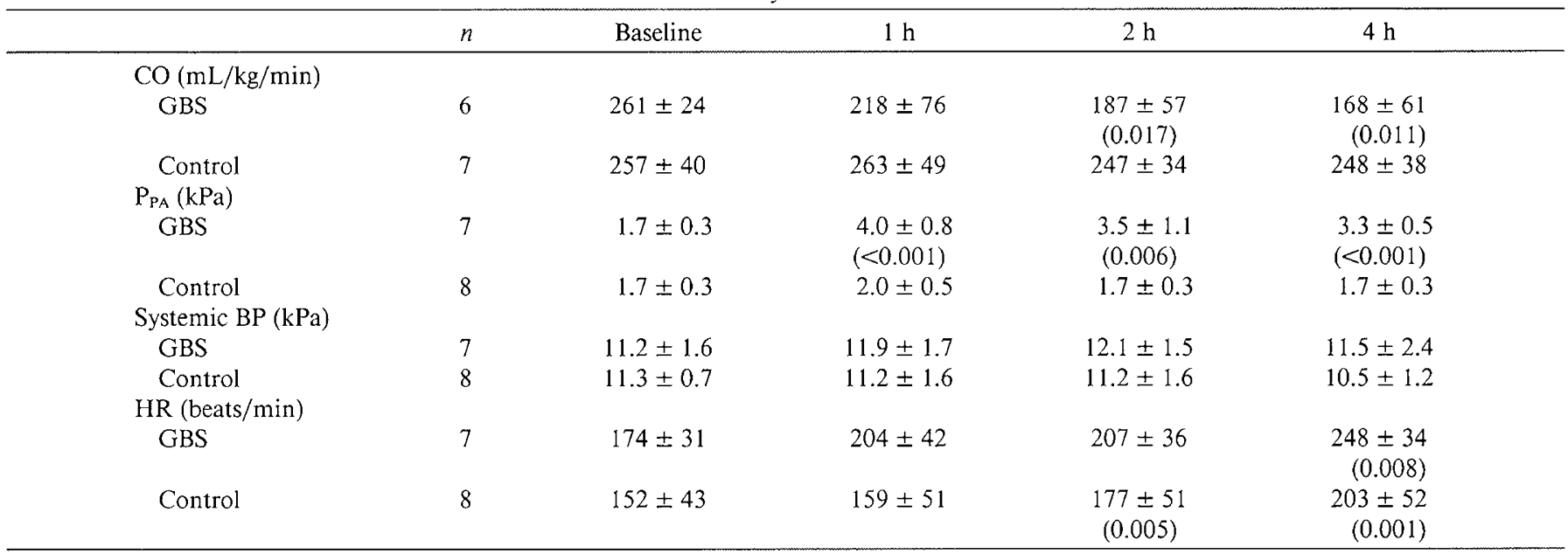

* All values are mean $\pm \mathrm{SD} ; n$, total no. of animals studied/experimental group; $p$ values are for paired $t$ tests $<0.02$ compared to baseline ( 1 mm $\mathrm{Hg}=0.1333 \mathrm{kPa})$.

Table 4. $Q d i^{*}$

\begin{tabular}{llllll}
\hline & $n$ & Baseline & $1 \mathrm{~h}$ & $2 \mathrm{~h}$ & $4 \mathrm{~h}$ \\
\hline Qdi-costal $(\mathrm{mL} / 100 \mathrm{~g} / \mathrm{min})$ & & & & & \\
GBS & 6 & $22.3 \pm 5.6$ & $20.7 \pm 8.9$ & $22.9 \pm 12.1$ & $20.2 \pm 8.0$ \\
$\quad$ Control & 7 & $20.7 \pm 5.3$ & $19.4 \pm 6.1$ & $19.8 \pm 7.5$ & $20.0 \pm 9.0$ \\
Qdi-crural (mL/100 g/min) & & & & & \\
GBS & 6 & $26.6 \pm 8.8$ & $27.3 \pm 10.1$ & $31.8 \pm 12.5$ & $27.0 \pm 8.9$ \\
Control & 7 & $33.2 \pm 13.3$ & $27.3 \pm 8.5$ & $32.2 \pm 10.1$ & $34.3 \pm 17.7$ \\
\hline
\end{tabular}

* All values are mean $\pm \mathrm{SD} ; n$, total no. of animals studied/experimental group.

Septic shock is often associated with uncompensated metabolic acidosis and hypercapnia $(1,20)$. In piglets, $\mathrm{PaCO}_{2}$ levels $>10$ $\mathrm{kPa}$ (75 torr) are associated with diminished Pdi (12) and, for this reason, a $\mathrm{PaCO}_{2}>8.7 \mathrm{kPa}$ (65 torr) at any point was chosen as an exclusion criterion for this study. No animals were excluded from either group for this reason. The GBS group did not vary over time in either $\mathrm{PaCO}_{2}$ or $\mathrm{pH}$ and did not differ from the control group in these measures. Maintenance of adequate oxygenation, tissue perfusion, and acid/base status was part of our experimental design, and this differs from previous work examining the effects of sepsis on diaphragmatic muscle function (13).

A canine model of endotoxemia demonstrated that an endotoxin bolus led to a decrease in Pdi, but this came just before the animal's death (1). The finding of a diminished Pdi was accompanied by hypotension, diminished $\mathrm{CO}$, hypoxemia, and an uncomnensated metabolic acidosis (1) - all conditions which have been associated with diminished Pdi in the $\operatorname{dog}(10,14,20-$ 22 ). Shock due to hypovolemia and/or tamponade is indistinguishable from endotoxemic shock in its effect on canine diaphragmatic function (21), suggesting that the secondary effects of shock might alone account for the decrease in Pdi attributed to endotoxin (1).

The effect of sepsis on Pdi in the rat has also been studied. Rats develop diminished Pdi $3 \mathrm{~d}$ after Streptococcus pneumoniae injection (2) and $2 \mathrm{~d}$ after injection of Escherichia coli endotoxin (3). In these two experiments, the decline in Pdi was seen despite maintenance of normal BP, suggesting that, in this case, the effects of shock were not to blame for the decline in Pdi. The effect of endotoxin on Pdi was prevented by indomethacin, a cyclooxygenase inhibitor (3). The eicosanoid products, prostaglandin $F_{2 \alpha}$ and prostaglandin $E_{2}$, induced during sepsis (4), have been shown to have a net catabolic effect on muscle (5). Yet the decrease in Pdi induced by endotoxin came despite no alteration in diaphragmatic mass or histology, whereas the nonrespiratory muscles demonstrated significant wasting (3). These data imply that eicosanoids may exert an effect on diaphragmatic function distinct from the effects associated with septic shock or muscle wasting. As the diaphragms of the rats in these studies were not obviously wasted, the decline in Pdi may reflect a late effect of sepsis upon muscle function, such as an alteration in the resting membrane potential or intramuscular electrolyte concentrations $(6,23)$.

An age-related susceptibility to GBS has been described in rats and humans $(8,9)$ in which the severity of the infection appears to be a function of the chronologic age of the host. In this experiment, we chose to study 2 -wk-old piglets, as the 2 -wk-old is still able to tolerate the extensive instrumentation required, whereas the newborn piglet is not. Both the 2- and 4-wk-old piglets (7) were given continuous GBS infusion at a mean rate of $5 \times 10^{8} \mathrm{cfu} / \mathrm{kg} / \mathrm{h}$. In the 2 -wk-old animals, though, levels of bacteremia were almost 40 -fold higher than in the 4-wk-old animals (7). A relative immaturity in white cell bactericidal activity or chemotaxis could account for the age-related difference in bacterial clearance (24). An altered regulation of the release of inflammatory mediators might also account for the age-related response seen $(25,26)$. One inflammatory mediator, $\mathrm{TNF} \alpha$, has been implicated in the alterations of Pdi during sepsis (27). Production of TNF $\alpha$ by piglets was not studied in this experiment, but in a similar GBS model, TNF $\alpha$ is a late-phase mediator only (28) and thus would not account for the early fall of Pdi at $1 \mathrm{~h}$ in this study.

In summary, our experiment sought to define the acute effects of GBS on diaphragmatic function that were separate from the effects of shock or chronic infection. For this reason, we used a dose of GBS known to cause pulmonary hypertension and the release of vasoactive and proinflammatory mediators, but that would not cause systemic hypotension, acidosis, or hypoxemia. Under these conditions, 2-wk-old piglets, in contrast to 4-wk-old piglets, demonstrated a decline in Pdi. These data demonstrate an age-related response to GBS in the piglet. This finding implies that a decline in Pdi during acute GBS infusion is not due to a secondary effect from shock (i.e. acidosis, hypercapnia, or hypoxemia), or the catabolic effects of a chronic infection, but 
rather to a direct effect of sepsis on diaphragmatic muscle function.

Acknowledgements. The authors thank James Jordan, Richard Tuck, Dong Ngyuen, and Susan Palmer for their assistance.

\section{REFERENCES}

1. Hussain SNA, Simkus G, Roussos C 1985 Respiratory muscle fatigue: a cause of ventilatory failure in septic shock. J Appl Physiol 58:2033-2040

2. Boczkowski J, Dureuil B, Branger C, Pavlovic D, Murciano D, Pariente R, Aubier M 1988 Effects of sepsis on diaphragmatic function in rats. Am Rev Respir Dis 138:260-265

3. Boczkowski J, Dureuil B, Pariente R, Aubier M 1990 Preventive effects of indomethacin on diaphragmatic contractile alterations in endotoxemic rats. Am Rev Respir Dis 142:193-198

4. Baracos V, Rodemann HP, Dinarello CA, Goldberg AL 1983 Stimulation of muscle protein degradation and prostaglandin $E_{2}$ release by leukocytic pyrogen (interleukin-1). N Engl J Med 308:553-558

5. Rodemann HP, Goldberg AL 1982 Arachidonic acid, prostaglandin $\mathrm{E}_{2}$ and $\mathrm{F}_{2 \alpha}$ influence rates of protein turnover in skeletal and cardiac muscle. $\mathrm{J}$ Biol Chem 257:1632-1638

6. Ruff RL, Secrist D 1984 Inhibitors of prostaglandin synthesis or cathepsin B prevent muscle wasting due to sepsis in the rat. J Clin Invest 73:1483-1486

7. Murphy TD, Mayock DE, Standaert TA, Gibson RL, Woodrum DE 1992 Group B streptococcus has no effect on piglet diaphragmatic force generation. Am Rev Respir Dis 145:471-475

8. Anthony BF 1985 Epidemiology of GBS in man. Antibiot Chemother 35:10 16

9. Zelig BJ, Armstrong CD, Walser JB, Bellanti JA 1982 Age-dependent susceptibility of neonatal rats to group B streptococcal type III infection: correlation of severity of infection and response of myeloid pools. Infect Immun 37:255263

10. Howell S, Fitzgerald RS, Roussos C 1985 Effects of uncompensated and compensated metabolic acidosis on canine diaphragm. J Appl Physiol 59:1376-1382

11. Watchko JF, LaFramboise WA, Standaert TA, Woodrum DE 1986 Diaphragmatic function during hypoxemia: neonatal and developmental aspects. J Appl Physiol 60:1599-1604

12. Watchko JF, Standaert TA, Woodrum DE 1987 Diaphragmatic function during hypercapnia: neonatal and developmental aspects. J Appl Physiol 62:768-775

13. Schnader JY, Juan G, Howell S, Fitzgerald R, Roussos C 1985 Arterial CO2 partial pressure affects diaphragmatic function. J Appl Physiol 58:823-829

14. Aubier M, Trippenbach $\mathrm{T}$, Roussos $\mathrm{C} 1981$ Respiratory muscle fatigue during cardiogenic shock. J Appl Physiol 51:499-508

15. Mayock DE, Watchko JF, Standaert TA, Woodrum DE 1990 Estimation of pleural pressure in the newborn. Pediatr Pulmonol 9:30-33

16. Standaert TA, LaFramboise WA, Tuck R, Woodrum DE 1985 The seria determination of lung volume in small animals by nitrogen washout. $J$ Appl Physiol 59:205-210

17. Heymann MA, Payne BD, Hoffman JIE, Rudolph AM 1977 Blood flow measurements with radionuclide-labeled particles. Prog Cardiovasc Dis 20:55-79

18. Rubens CE, Wessels MR, Heggen LM, Kasper DL 1987 Transposon mutagenesis of type III GBS: correlation of capsule expression with virulence. Proc Natl Acad Sci USA 84:7208-7212

19. Gibson RL, Redding GJ, Truog WE, Henderson WR, Rubens, CE 1989 Isogenic group $\mathrm{B}$ streptococci devoid of polysaccharide or $\beta$-hemolysin: pulmonary hemodynamic and gas exchange effects during bacteremia in piglets. Pediatr Res 26:241-245

20. Roussos C 1986 Diaphragmatic fatigue and blood flow distribution in shock Can Anaesth Soc J 33:S61-S64

21. Hussain SNA, Roussos C 1985 Distribution of respiratory muscle and organ blood flow during endotoxic shock in dogs. J Appl Physiol 59:1802-1808

22. Magder S, Lockhat D, Luo BJ, Roussos C 1985 Distribution of blood flow with inspiratory loading and shock. J Appl Physiol 58:1148-1156

23. Sayeed, MM 1987 Ion transport in circulation and/or septic shock. Am J Physiol 252:R809-R821

24. Kretschmer RR, Stewardson PB, Papieriak CK, Gotoff SP 1976 Chemotactic and bactericidal capacities of human newborn monocytes. J Immunol 117:1303-1307

25. Glover DM, Brownstein D, Burchett S, Larsen A, Wilson CB 1987 Expression of HLA class II antigens and secretion of interleukin- 1 by monocytes and macrophages from adults and neonates. Immunol 61:195-201

26. Burchett S, Weaver W, Westall J, Larsen A, Kronheim S, Wilson CB 1988 Regulation of tumor necrosis factor/cachectin in human mononuclear phagocytes. Immunology 140:3473-3481

27. Wilcox PG, Osborne S, Bressler B 1991 Diaphragmatic contractility is impaired by inflammatory secretory products. Am Rev Respir Dis 143:A126(abstr)

28. Gibson RL, Redding GJ, Henderson WR, Truog WE 1991 Group B streptococcus induces tumor necrosis factor in neonatal piglets. Am Rev Respir Dis 143:598-604 